\title{
Networked learning in higher education: practitioners' perspectives
}

\author{
Chris Jones, Mirea Asensio and Peter Goodyear \\ Advanced Learning Technology, Lancaster University \\ email:c.r.jones@lancaster.ac.uk
}

There is a growing use of a variety of communications media to provide networked learning in higher education. The practitioners in the field vary from experienced educators who have many years' experience to early adopters who have begun to use networked technology for teaching and learning recently. Using interviews informed by a phenomenographic approach, this paper investigates the varieties of experience of practitioners of networked learning. It reports initial findings that represent an early stage of analysis. The findings point towards a common philosophy held by current practitioners of networked learning but a lack of 'rules of thumb'. Practitioners expressed ideas close to a new paradigm in education but were cautious about specific design outcomes meeting expectations. This finding raises questions about design and whether networked learning is yet stable enough a field to provide guidance on best practice. The paper also reflects on criticisms of the phenomenographic method, in particular its reliance on interview data, and offers some possible ways of dealing with the criticisms.

\section{Introduction}

This paper arises from the work of the JISC Committee on Awareness, Liaison and Training (CALT)-funded 'Networked Learning in Higher Education' project. Networked learning is a term that has had a currency for some years now and can be seen as part of the development of a new paradigm in education (Harasim, Hiltz, Teles and Turoff, 1995; Koschmann 1996; Romiszowski and Ravitz, 1997). We have defined networked learning as learning in which C\&IT is used to promote connections: between one learner and other learners; between learners and tutors; between a learning community and its learning resources.

As part of the background for the main investigations into students' experiences, we are also conducting a 'mapping' exercise, which locates and describes examples of the use of 
networked learning in UK higher education. The mapping exercise also involves interviews with a wide variety of $\mathrm{HE}$ teaching staff to get a sense of their perspectives on current and future uses of networked learning. This paper focuses on a small subset of these interviews. The space of possibilities for networked learning is vast, for this reason the project has identified some priority areas on which attention should be focused:

- the use of asynchronous communications technologies to support collaborative learning among geographically and /or temporally distributed groups of students;

- the use of synchronous video communications to allow remote access to live lectures and demonstrations;

- approaches which mix the use of Web resources with asynchronous or synchronous interpersonal communication.

In this paper we report on accounts by practitioners who all made use of text-based communication systems provided over the Internet. All courses were available using Web access, either primarily or as a supplement to a client-server system, and some had Web resources that were distinct from the conferencing system itself. The interviewees had at least two academic years' experience of the use of networked learning. They ranged from experts who had used a variety of systems for a long period of time to early adopters who have deployed courses over recent years.

\section{Methodology}

The project is informed by a phenomenographic approach and this provides a link between the various aspects of the overall project. Ference Marton explained phenomenography as a research approach for understanding people's ways of experiencing the world. He defined the approach as:

the empirical study of the differing ways in which people experience, perceive, apprehend, understand, or conceptualize various phenomena in, and aspects of, the world around them. (Marton, 1994, p. 4424)

The aim of phenomenography is to describe qualitatively different ways of experiencing phenomena, in this case practitioners' experiences of networked learning. The objective is to illuminate the variations in ways of experiencing networked learning (Marton and Booth, 1997; Laurillard, 1993). Whilst this approach is not widely used outside educational research it has a long history in an educational context. Phenomenographic research has an important place informing theories of teaching and learning and focuses particularly on student activity (Biggs, 1999). Recently phenomenographic research has been extended to investigate the role of teachers in relation to student activity (Prosser and Trigwell, 1999). The phenomenographic approach is particularly suited to our aims as the project is investigating both student activity and practitioners' accounts of their activity.

We report interviews with practitioners carried out as part of a mapping exercise, which attempts to situate our research investigating student experiences within a 'snapshot' of the spread and use of networked learning in higher education in the UK. The interviewees were not intended to be a sample of networked learning users and were recruited opportunistically within the categories outlined in the introduction. The aim of the 
research is to illuminate rather than to provide a systematic sample of current practitioners' views.

This initial report relies on interviews with ten practitioners from eight departments in five universities that were conducted during a six-month period. The interviews were approximately one hour in duration and focused on the practitioners' use of networked learning technology to deliver a particular course. The interviews were largely unstructured though the interviewers had a loose schedule or format that provided some consistency between interviews and indicated key areas of interest. The interviews were conducted as a dialogue and each interview began with a request for the practitioner to explain a course that they had taught using networked learning. Practitioners were encouraged to use prompts such as course documentation and online access to course materials during the interview. The interviewer tried to intervene as little as possible and concentrated on asking questions that provoked reflection by the respondent on their own experience.

The emphasis in the interviews we conducted was in stimulating the practitioner's reflection upon their experience. This conforms to Marton's view that the phenomenographic interview provokes a change from unreflected to reflected awareness (Marton, 1994). In the interview, the aim was to 'make things which are unthematized and implicit into objects of reflection, and hence thematized and explicit' (Marton, 1994, p. 4427).

The analysis of the interview data has concentrated on the written transcripts of the interviews taken verbatim from audio recording. The interviews have been examined for variations in the experiences of the practitioners and to try and identify emergent elements that might be common between them. The analysis focused on both variation and the possibility of a limited number of types of variation being present. The transcripts have been analysed from the point of view of the phenomena (networked learning) rather than the individual interview. The separations between individual accounts have been temporarily abandoned. The individual accounts are likely to vary internally and each interview might provide variations within itself as well as between different interviews. It is expected that later analysis will look at the individual interview as a unit of analysis. The analytic process in phenomenographic research is iterative, once categories of description are found they can be reapplied to the data from which they originate. The results reported in this paper are an initial set of categories that have been generated and they are currently being reapplied to the data and reported back to participants.

Phenomenographic research has been criticized from an ethnomethodological perspective for its reliance upon the interview (Fleming, 1986). Fleming gives an example of 'versions' - that is, of an individual giving a series of accounts of one event to a variety of audiences. Each account is different; each is fitted to its particular purpose and might appear to be out of place in another setting. The point being that all accounts are partial, that they point towards something but cannot contain all the information required for a complete description of that which is being described. So in the example chosen by Fleming an account given by a student to his mother of the day's events would not be replaceable by the account given to his tutor of the same day's events. The accounts may both be truthful and accurate in the context of their use. This raises the question of the status of the interview and the reliance we have placed upon it in this research and in phenomenography more generally. 
A recent critical review of phenomenography gives both a useful review of phenomenographic research and offers a 'constructionist' revision of traditional phenomenographic approaches (Richardson, 1999). Richardson argues that conceptions of reality are discursive practices, which may be used as resources in particular communicative encounters, rather than psychological entities that reside in the minds of individuals (p. 72). Richardson argues for more attention to be paid to accounts given by participants in real-life situations. We would agree with this point but would argue further that viewing interviews as situational and paying attention to the context of the interview itself will help to deal with Fleming's criticism of interview-based data. Unlike much phenomenographic research we adopt a sceptical stance towards statements made by interviewees, accepting that the accounts given are indeed versions fit for the purpose of the interview. We will point to some ways in which we believe the contextual nature of the interview has affected the research we have conducted. We none the less believe that the accounts given by practitioners examined in the ways we have outlined can provide us with some valuable insights. In particular we believe interviews can be treated as reports of the resources that practitioners have available for action. In order to demonstrate this we set out below some preliminary findings.

\section{Findings}

The practitioners interviewed were from a number of HE backgrounds, six taught using networked learning at postgraduate level and four at undergraduate level. Most had considerable experience in this field, up to ten years, and the less experienced had used networked learning for at least two academic years. Practitioners taught in eight departments including law, information technology, library and information studies, education and management.

\section{Tight and loose structures}

Respondents identified a problem of course design and administration that we have tentatively designated 'tight-loose'. They were concerned with how to organize students and how much to organize students. Within the respondents' accounts the issue was often seen as involving either tight or loose structures. Practitioners had often experienced courses that had not run as they expected and in later iterations, or in plans for future iterations, referred to changes in the structures of enforcement. Assessment criteria and course requirements, such as attendance at face-to-face sessions or active participation online, were the common examples of the concerns about structure and enforcement.

The problem was identified in a number of ways with an underlying issue concerning mutual expectations. Two illustrative quotes concerning 'tight' structures are given below:

Part of the point of having a very tight structure was to encourage people to participate in, in a much more, well in a way in which the mutual expectations are more clearly understood. [John]

The reason for setting the deadlines and structuring a timetable has been in response to one of the problems which arose the previous year which was that one team would post a load of messages to the other teams and then have to sit and wait for three days before the others bothered to reply because that team happened to be better organized, so the structuring of the exercises in terms of the time schedule has been and I think necessitated in order to actually save them from wasting their time. [Norman] 
The practitioners expressed concerns with how to organize students so that they could anticipate each others' actions and co-ordinate their work. This concerned the use of deadlines, whether to provide detailed instructions on the work to be done and whether to enforce or encourage rates and types of participation. For example:

We've tried to structure it fairly tightly and we may tighten that up even more this year ... the downside of that I think is that with the tighter the schedule the more structured the exercise is and there is a danger that you're damping down on the potential for creativity and the extra time of the research that might be produced in that extra time, if you see what I mean, but there's a fine balance to be drawn there, ... [Norman]

The choice of a loose rather than a tight structure was also associated with attempts to refine assessment structures. Practitioners who had experience of assessment being used to engineer participation or interaction were concerned about its consequences either in terms of workload or in terms of unintended consequences:

One of the dominant issues was that we began to believe that our programme was heavily over-assessing students, that created more work for them and more work for us. [John]

What they begin to see is or what they seem to see is the fact that the tutor wants to see them interacting online and our experience has been that they will work together offline and then come into the lab and they'll put the stuff up onto the conferencing system which is supposed to show that they are learning online. But they're not, they're doing that for your benefit or because that's what their perception is. [Jack]

Looser structures were in part responses to the perverse effects that structured interventions had, which undermined the course designers' intentions. Overall the concern with structure could be seen as a response to gaps between design intentions and actual outcomes.

\section{Disappointment}

Related to the practical issue of how formally structured a networked learning environment might need to be was a common articulation of disappointment at the actual experience of the course when compared with expectations. We look at expectations more closely in the following section and in this section examine what factors influenced respondents in expressing disappointment.

Disappointment was a common but not a universal feature. Low participation was the reported factor related to disappointment, and practitioners who did not experience low participation did not express disappointment with course outcomes. The structural variations proposed by practitioners were driven by views on students' motivations to participate. Overall practitioners had a problem relating their design expectations to the outcomes that they experienced, a particularly clear example is provided below:

What else um I certainly haven't yet learnt how to do it so I so I still don't know how to create an online learning environment that would work in the way I imagined it might. There are probably trivial examples where I can get things to pan out the way I want but I think you find this quite common that people however much experience they have developed, however many articles they write about good ways of doing things, however 
much they analyse student experiences, it's still extremely difficult to design an online environment and online course activities in ways where you are not surprised and/or disappointed by the output. [John]

Two of our respondents stood out as not experiencing the same disappointment as others. Their use of networked learning was at postgraduate level and was informed by a very consistent educational theory that had initial 'tight' structures, for example compulsory participation and residential sessions, but then allowed a greater degree of freedom in course dynamics once the base expectations were set. The educational philosophy they had was similar and both programmes embodied a strong group ethos. Participation in these courses was obligatory. In response to the question 'How is participation - is it high or is it low?' Tim answered:

Well it varies I think um from person to person but no one can get through the course without participating and they know that so that's one factor. I think in some courses that use computer conferencing, at the OU for instance, you can take the course and do nothing in the computer conference and still get through the course. In ours you couldn't. That's a difference but it's incredibly high I mean sometimes it's just too much. [Tim]

This contrasted sharply with the majority of respondents who expressed disappointment related to low rates of participation.

In this module there is a very clear design assumption that everyone would participate in the online environment and that they will do that in quite a highly structured way... it's not uncommon in previous modules for the online activity to be seen by the students as entirely optional. The majority of them wouldn't participate at all in any one module and if you look back over the last two years on the programme under half of the students that could participate in the online activity did so. So this is actually better than that, but it's not as good as I hoped for when I was designing it. [John]

The concern with low rates of participation and the discussion of 'tighter' structures fed the sense of disappointment. An illustration of this link can be found in the following comment:

the fundamental questions of student participation and participation by all the students in it um remain unresolved as they ever were in some ways ... It's making me question um whether the structure is the way to encourage participation, so by having set tasks and activities and demanding that the students or even making this stronger and saying you must contribute is that the way to go forward. [Alice]

Stronger enforcements were part of a wider rethinking of principles and related to perceptions of students' motivations as instrumental:

I certainly think I've had to rethink things that I believed in. From a liberal education point of view that people were here because they wanted to learn and now I don't know, I'm not sure that they will do this module because they want to learn about it. They'll do this module because they want a specific grade to get the specific final degree. [Robert] 
The expression of surprise and disappointment were reported as a response to levels of participation and more generally to the ability to design to anticipate outcomes in a networked learning environment.

\section{Expectations}

Perhaps the underlying issue behind disappointment was connected to the type and level of expectations of our practitioners. As interviewers we had our own expectations and one was that the practitioners might vary between those who were pioneers and had become expert in the use of networked learning and those who were more recent adopters. It became apparent on reading the transcripts that there was a common 'philosophy' or educational approach that underpinned their work. This could be reduced to a series of bullet points including:

People learn

- collaboratively by articulating and sharing their ideas, experience and expertise through discussion and dialogue;

- by linking ideas from literature, online contributions and their own practice and experience;

- by doing, by engaging with the activity or task;

- from experience, either positive or negative and from exposure to different tutoring and learning styles.

It can be seen from this list of points that the practitioners have a relatively common educational outlook that may be particular to them or reflective of this particular time and place. The outlook expressed is similar to that described as the emergent computersupported collaborative learning paradigm by Koschmann (1996).

The types of assumptions about learning that we found are illustrated below:

One of the things that we want is for people to learn from each other, get insights into their own work by hearing about other peoples' work ... um . . . actually giving some of their background is really quite useful. [John]

We encourage students to use it [online environment] to share their experiences and their expertise. [Alice]

[The programme] is very much focused around the personal development or professional development and works a lot in the area of relationships and discussion and dialogue. [Penny]

We decided we were going to develop a course like this and what we wanted to do was, we wanted to sort of turn in on itself so they could learn about developing teaching and learning systems by experiencing a number of teaching and learning systems. [Robert]

All the practitioners except one either mentioned constructivist or collaborative approaches to learning, many expressed their ideas in terms of communities of practice. The one respondent who made no mention of such approaches was using a combination of Web pages and individual email to promote a dialogue in the form of philosophical letters with the students. A wide variety of pedagogical techniques have been associated with 
networked learning and it is surprising to find such a narrow range of underlying approaches adopted by the practitioners (Paulsen, 1995).

In relation to expectations we have found that practitioners often referred to students as being 'good students', 'compliant students', and 'motivated students'. We found that these descriptions of students were related to the student matching or not matching with the educational philosophy or approach of the course/programme. Thus, for instance, when discussing assessment a practitioner said the following:

This is another issue I find very difficult about assignment marking. Students who feed back the party line about collaborative learning and whatever and I don't mean just feed it back in a sense of hype and stuff but people who have clearly seen the benefits of collaborative learning. It's hard not to give them high marks because this is what we are trying to teach people, the value of collaborative learning. However people who don't see it and don't want to and stand out against collaborative learning ... I've only seen ones that I could, you know bending over backwards, give 60 to because I'm trying to not be biased against them. [Elaine]

Several practitioners described collaborative learning as a 'problem'. Student resistance concerned some whilst others were concerned by a lack of clarity among other practitioners about what 'collaboration' might mean. Overall practitioners identified collaboration as an aim but were concerned that it was difficult to achieve and difficult to conceptualize. Collaboration and participation were both features that exemplify the gap that practitioners experienced between expectations and outcomes.

\section{Discussion and conclusions}

We suggest that the issue of tight vs. loose structures that permeated the interviews may be a significant issue for practitioners. Whilst the practitioners expressed a similar common philosophy or paradigm they did not have a stable repertoire of 'rules of thumb', of reliable design guidelines. In a traditional or face-to-face setting expectations are in some ways common sense or common knowledge (Edwards and Mercer, 1987). Participation in lectures and seminars, whilst not unproblematic, has a set of commonly understood assumptions about attendance and behaviour. This should not be taken to imply that we fully understand face-to-face settings or that we endorse common-sense views of such settings, only that such shared expectations are present in face-to-face contexts. The boundaries within a networked setting appeared less commonly understood and each practitioner had comments to make about how they had varied their own practices between tight and loose structures to try and remedy outcomes they had not expected.

Practitioners articulated their experience in terms of either loose or tight structures. We would suggest that a reconception might be possible in terms not of an either/or dichotomy but in terms of a number of trade-offs. The use of loose elements in one area might require the use of tight structure elsewhere. Practitioners might be able to make informed choices not between enforcement and free expression but how and where to enforce in order to allow free expression elsewhere (cf. van Driel, Verlop, van Werven and Deckers, 1997; Goodyear and Steeples, 1992). Some support for this view was found in the two practitioners who did not express disappointment at low rates of participation. Their 
courses exhibited tight initial structures and compulsory participation but then allowed relative freedom in a loosely structured environment. In our further analysis we will look for the precise ways in which structures and enforcement are discussed. For example, most practitioners reported that residential sessions were essential for building a learning community. In order for people to be able to contribute online and be comfortable with the medium it was felt they needed to have met their colleagues face-to-face in the first instance. The ability to maintain face-to-face sessions was a reported problem for courses that were becoming more international and Web-based.

We wonder why both expert practitioners and early adopters display a common educational philosophy. That philosophy may not be well understood or accepted outside this narrow and possibly self-selected group. The disappointment we found expressed may have implications for a large-scale roll out of new technologies. Disappointment if widely experienced by new practitioners in the field of networked learning, could lead to resistance to the adoption of networked learning in the future. Already there is evidence that students experience distress and frustration in networked environments and that these experiences may inhibit their educational opportunities (Hara and Kling, 1999). The practitioners' common educational philosophy and the theories that provide the rationale for the paradigm of networked learning may not be well understood in the intended audience for educational technologies. This would raise questions of staff development and suggest that it required significantly more than simple training in the technology.

Our findings help us to comment on the general approach of phenomenography. The accounts we were given were specific to the situation. We were offered a particular example of this by one respondent who pointed to another interview she had given within days of the interview with us and commented on how she had reported her experiences differently in the second interview. Other respondents have written accounts of their courses, for example as case studies, which vary from the accounts we were given. We believe that this does not invalidate the data gathered by interview. However, it must make us cautious in what we claim interview data represents. We do not believe, for example, that the interview reveals any fixed internal state. This finding tends to support the characterization of interview accounts as versions provided by Fleming (1986). More positively we claim that the interview reveals some of the resources for action available to the respondent. These resources may or may not be used to inform practice and may provide an after-the-event rationalized account rather than motives prior to action. The interviewees display the characteristics of reflective practitioners and we cannot be sure that the movement from unreflected to reflected awareness was achieved in the interviews. This is an important finding as Marton has relied on this transition from unreflected to reflected or metaawareness in his defence of the interview from its critics (Marton, 1994; Marton and Booth, 1997, pp. 129-32). Most of the interviewees have written about their experiences and had previously reflected upon the issues that the interview raised. The accounts we heard were in some senses a performance of previously rehearsed ideas.

Finally we would like to comment on the idea of good or 'best' practice. Practitioners generally expressed a concern that they did not fully understand the relationship between their educational designs and their outcomes. It might be that there is not yet sufficient common agreement or a common-sense view of educational practice in a networked 
environment. This may mean that rather than a best practice or even a singular good practice we may find various good practices, each fit for particular purposes. In which case the best we may be able to distil from practitioners' reports of their practice will be rules of thumb. Design of learning environments may well be revealed as an iterative process in which there is continuous identification of problems and modifications of practice.

\section{Acknowledgements}

This work was partially funded by a grant from the Committee on Awareness, Liaison and Training of JISC (the Joint Information Systems Committee of the UK higher education funding councils). The views expressed here are not necessarily those of JISC or CALT. Further information about the project can be obtained from the project's website (http://csalt.lancs.ac.uk/jisc/). We would like to acknowledge the contributions of other members of the project team: Vivien Hodgson, Christine Steeples, Susan Armitage, Mark Bryson, Michael O'Donoghue and David Hutchison. We would also like to acknowledge the contribution of the two anonymous reviewers to the development of the paper.

\section{References}

Biggs, J. (1999), Teaching for Quality Learning at University, Buckingham: SRHE and Open University Press.

Edwards, D. and Mercer, N. (1987), Common Knowledge, London: Methuen.

Entwistle, N. J. and Ramsden, P. (1983), Understanding Student Learning, London: Croom Helm.

Fleming, W. G. (1986), 'The interview: a neglected issue in research on student learning', Higher Education, 15, 547-63.

Goodyear, P. and Steeples, C. (1992), 'IT-based open learning: tasks and tools', Journal of Computer Assisted Learning, 8 (3), 163-76.

Harasim, L., Hiltz, S. R., Teles, L. and Turoff, M. (1995), 'Network learning: a paradigm for the twenty-first century', in Harasim, L., Hiltz, S. R., Teles, L. and Turoff, M. (eds.), Learning Networks: A Field Guide to Teaching and Learning Online, Cambridge, MA: MIT Press, 272-8.

Hara, N. and Kling, R. (1999), 'Students' frustrations with a Web-based distance education course', First Monday, 4 (12), http:Ilfirstmonday.org/issues/issue4_12/haralindex.html.

Koschmann, T. (ed.) (1996), CSCL: Theory and Practice of an Emerging Paradigm, Mahwah,NJ: Lawrence Erlbaum Associates.

Laurillard, D. (1993), Rethinking University Teaching: A Framework for the Effective Use of Educational Technology, London: Routledge.

Marton, F. (1994), 'Phenomenography', in Husen, T. and Postlethwaite, T. N. (eds.), The International Encyclopedia of Education, Second Edition, Oxford: Pergamon, 4424-9.

Marton, F. and Booth, S. (1997), Learning and Awareness, Mahwah, NJ: Lawrence Erlbaum Associates. 
Paulsen, M. F. (1995), The Online Report on Pedagogical Techniques for ComputerMediated Communication, http://home.nettskolen.nki.no/ morten/: (last accessed 17 Sept. 1999).

Prosser, M. and Trigwell, K. (1999), Understanding Learning and Teaching: The Experience in Higher Education, Buckingham: SRHE and Open University Press.

Richardson, J. E. T. (1999), 'The concepts and methods of phenomenographic research', Review of Educational Research, 69 (1), 53-82.

Romiszowski, A. J. and Ravitz, J. (1997), 'Computer mediated communication', in Dills, C. R. and Romiszowski, A. J. (eds.), Instructional Development Paradigms, Englewood Cliffs, NJ: Educational Technology Publications, 745-68.

van Driel, J. H. Verloop, N., van Werven, H. I., and Dekkers, H. (1997), 'Teachers' craft knowledge and curriculum innovation in higher engineering education', Higher Education, $34(1), 105-22$. 